\title{
Public Perceptions about the Impact of Climate Change on Human Health: A Study of Bangladesh
}

\author{
Bikram Biswas $^{1}$, Sajib Kumar Roy ${ }^{2}$ \\ ${ }^{1}$ Lecturer, Department of Educational Administration, Noakhali Science and Technology \\ University, Bangladesh. \\ ${ }^{2}$ Sajib Kumar Roy, Lecturer, Department of Development Studies, Hajee Mohammad Danesh \\ Science and Technology University, Dinajpur, Bangladesh.
}

\section{E-mail: *bikram.ea@nstu.edu.bd ${ }^{1}$, sajib@hstu.ac.bd ${ }^{2}$}

\begin{abstract}
:
The main purpose of this research is to analyze the perception of climate change impacts on human health in Bangladesh through data from nationality representative surveys conducted in some district of Bangladesh. In Bangladesh there have a few research has been conducted on public perceptions about the impact of climate change on human health. A structured questionnaire method was conducted, and data collected from 615 respondents. The findings of this study reveal that out of 615 respondents, $76.0 \%$ of the respondents replied positively while remaining $24.0 \%$, almost one-fourth of total respondents, indicated that they have not heard the term climate change before. Knowledgeable in climate change, $92.5 \%$ of respondents agreed that climate change has an impact on human health while only $7.5 \%$ respondents disagreed with this statement. $90.5 \%$ of respondents argued that they are agreed with the opinion that climate change is a serious threat to human health.
\end{abstract}

\section{Keywords: Public Perception, Climate Change, Human Health, Bangladesh}

\section{Introduction:}

Bangladesh is a densely-populated, mainly riverine and low-laying country located in South Asia. The country's total land size is 147,570 square kilometers (Bangladesh Bureau of Statistics (BBS, 2019a), which is relatively small compare to its neighbor. The environmental issue is currently one of the most significant issues on the global political and economic agendas. The poor people are the most vulnerable to the impact of environmental issue. On the other hand, In Bangladesh, the environmental issues lower the value of and excess to productive resources and create health problems as well mainly for the poor, which increases vulnerability and complicate economic development and the fight against poverty. The climate 
of Bangladesh is a subtropical monsoon climate and characterized by wet, and dry seasons. Particularly, Winter, Summer and Monsoon are prominent among the six seasons in a year in this country. In winter, generally begins in November and ends in February, the minimum temperature fluctuates within the range from 7 degrees Celsius to 13 degrees Celsius where the maximum temperature in this season surges within the range from 24 degrees Celsius to 31 degrees Celsius. In Summer (March - June), the average maximum temperature is 37 degrees Celsius because the temperature sporadically rises up to 41 degrees Celsius or more in some places in this season. $80 \%$ of the total rainfall occurs in the Monsoon period which usually starts in July and stays up to October, while the average annual rainfall differs from 1429 to 4338 millimeters. The maximum rainfall is observed in the northern part of Sylhet and the coastal areas of Chattogram, while the minimum is recorded in the northern and western parts of the country (BBS, 2019b). Bangladesh regularly experiences almost all types of natural hazards including floods, drought, heavy rain, heavy storms, riverbank collapse, fire incident and epidemics affecting people as well as their assets repeatedly all most every year and putting the country's economy at high risk (Oudry, Pak \& Chea, 2016).

Bangladesh has done poorly in the 2020 edition of a recent environment report, ranking dismal 162 out of 180 countries worldwide; the country returned one of the lowest environmental performance index scores in the region (EPI, 2020). The government of Bangladesh has paid deep consideration for a long time not only national but also sub-national levels to address the challenges posed by climate change. Moreover, Bangladesh has recognized the importance of environmental protection and climate change in economic development efforts (MoEFCC, 2018). Besides, the impact of climate change on biodiversity in Bangladesh is yet to be determined but likely to induce significant changes to the health of ecosystems, and to the rural communities who depend on natural resources for their livelihoods (MoEFCC, 2018). It seems to be relatively little research on public awareness and understanding of the human health impacts and risks associated with climate change and almost none of the research has been published or synthesized in the academic literature. Furthermore, people in developing nations were more likely to cite health impacts as a concern than people in developed nations (Akerlof et al., 2010). The considerable impacts of climate change are expected to affect human health which including increased vector-borne, water-borne and food-borne diseases; injuries and deaths caused by extreme hydro-geological events; heat-related diseases and deaths caused by heatwaves; and negative impacts on malnutrition (Markandya \& Chiabai, 2009). This research explored to find out the public knowledge of climate change in Bangladesh, public perceptions 
and awareness of climate change affecting human health, to find out the perception about the relationship between climate change and diseases and to find out the public attitudes towards climate change policies of Bangladesh.

\section{Literature Review}

Public Perception (PP) is known as the social phenomenon; PP can be seen as the differences between an absolute truth based on facts and a virtual truth shaped by popular opinion, media coverage, and reputation. Similarly, PP is simply defined as the type of information obtained from a survey of public opinion which is merely the aggregate views of a group of people who are asked directly what they think about particular issues or events (Dowler et al. 2006). Besides, based on business dictionary, perception is defined as the process by which people translate sensory impressions into a coherent and unified view of the world around them though necessarily based on incomplete and unverified information, perception is equated with reality for most practical purpose and guides human behavior in general. On the other hand, Cambridge Dictionary defined perception as a belief or opinion, often held by many people and based on how things seem; or the quality of being aware of things through the physical senses, especially sight, also defined as someone`s ability to notice and understand things that are obvious to other people.

Climate Change (CC) refers to a change in the manner of the climate which might be identified by the changes in the mean or the variability of its properties which persists for an extended period, especially decades or longer. CC may be due to natural internal processes or external forcing to persistent anthropogenic changes in the composition of the atmosphere or land use. The climate is the typical or average weather of any local areas or regions, so climate change is defined as the change in the typical or average weather of region or city; for example, this could be a change in a regions average annual rainfall, or it could be a change in a city's average temperature for a given month or season. Moreover, CC is also explained as any long term change in Earths overall climate; this could be a change in Earth's average temperature or a change in Earth's typical precipitation patterns. On the other hand, climate change impacts (CCI) refers to the consequences of climate change on both natural and human systems; CCIs include potential impacts, residual impacts, aggregate impacts, market and non-market impacts (Bose, 2017). CC means a change of climate which is attributed directly or indirectly to human activity that alters the compositions of the global atmosphere and which is in addition to natural climate variability observed over comparable periods (Protocol, 1997). 
Human Health $(\mathrm{HH})$ is a state of complete physical, mental, and social well-being and not merely the absence of disease or infirmity (WHO, 1948). Its definitions present three major interrelated components of health; the physiological refers to the functionality of the body biological system while mental focus on the human psychological, emotional and intellectual state; in additions, the social wellbeing is the ability to connect and the function of as a member of society (Amzat \& Razum, 2014). Saracci (1997) proposed the definition of health as "a condition of well-being, free of disease or infirmity and a basic and universal human rights." Impliedly, this definition also considered those who are living positively with chronic disease as unhealthy; it presents health as a basic right and problematic. Furthermore, the Cambridge Dictionary defined the term health as the condition of the body and degree to which it is free from illness or the state of being well. On one hand, health was defined as, "a dynamic state of well-being characterized by a physical and mental potential, which satisfies the demand of life commensurate with age, culture and personal responsibility (Bircher, 2005). It plays a crucial part in poverty reduction; the absence of good health is both a cause and consequence of poverty.

\subsection{Impacts of Climate Change}

\subsubsection{World Perspective}

"Climate change threatens water, sanitation and hygiene facilities, and services"; floods, and droughts, polluting, and reducing water delivery respectively, have now become a perennial issue to deal with in the northern regions of Ghana. Moreover, $\mathrm{CC}$ affects not only surface water but also groundwater as well (Alhassan \& Hadwen, 2017). The impacts of CC on agriculture, forestry, water management, and human settlements are a growing concern in Romania (Teodorescu \& Oros, 2010). CC impacts on river discharge are vitally important in Ukraine; the results indicate the temperature increases and earlier snowmelt will increase in river discharge in the winter season and decrease in the spring (Didovets et al., 2017).

Moreover, climate change is a significant and emerging threat to human health, especially where infectious diseases are involved. Markandya and Chibai (2009) mentioned that the huge implications of CC for human health include thermal related morbidity and mortality in terms of extreme temperatures, effects related to air pollution, extreme weather events impact, malnutrition, water-borne, and vector-borne diseases. Direct impacts of CC on human health result in human injuries, illness, and death related to extreme weather events and changes in 
weather patterns rise in infectious diseases and increased diseases burdens whereas indirect impacts are food security and nutrition, displacement and loss of livelihoods leading to negative health effects ( Akerlof et al., 2015).

A study conducted by Chhinh and Cheb (2013) measures the household's vulnerability to climate change among communities in Kampong Speu Province (KSP), Cambodia by using three indicators including, exposure, sensitivity, and adaptive capacity while the exposure is quite low. The results of the survey from 630 households showed that drought is the pronoun hazard in KSP whereas livelihood and infrastructure are more sensitive. Besides, households are living in highland seem to be more vulnerable than low land residents (Chhinh and Cheb, 2013). Chhinh and Poch (2012) found that more than 60\% of households in KSP are vulnerable to climate change and among the exposure to natural hazards in Cambodia, drought posed a high risk. Uniquely, a study by Chean (2017) found that the farmers had little knowledge and understanding of $\mathrm{CC}$ and its adaptation strategies in Takeo Province while they had good perceptions of risk and adverse impacts of extreme weather events on their health, food, life and economic activities. Further results demonstrated that some health-related issues such as heat-related stress, anxiety, and concern were caused by extreme weather events. On the other hand, Bangladesh is prone to flooding, drought, and windstorm, the frequency and intensity of which appear to have increased since 1988 when statistics began to be regularly recorded. These disasters and climate-related hazards have exacted huge socioeconomic costs on the country's economy and people's livelihoods (Sour \& Phalla, 2014).

Furthermore, there are some studies about public perceptions of climate change in different countries. For instance, a study by Tvinnereim et al. (2017) confirmed that Chinese respondent's climate change has negative impacts on humans, and most of them aware of the difference between the physical manifestation of air pollution and global warming with connected smog and sea-level rise. Likewise, Toan et al. (2014) found that the most symptoms were headaches, fatigue, and dizziness as well as hypertension and other cardiovascular diseases; additionally, the majority of the respondents had heard about climate change and its impacts on human health in Hanoi, Vietnam. Growing evidence suggested that climate change affects human health through the increase in floods, storms, fires, and droughts in the south, and southeast Asian least developed countries (LDCs) Like Nepal, Cambodia, Lao PDR have also been suffering from increasing droughts arising out of delayed and changing distribution patterns of precipitation (Miyan, 2015). As like, Pillay and van den Bergh (2016) also 
confirmed that human health was seriously affected by storms, floods, and droughts as they restrict food production and water supply.

Al Buloshi and Ramandan (2015) studied about public awareness and knowledge on climate change amongst the inhabitants of Muscat governorate in Oman by using descriptive statistics as the main analysis technique revealed that public awareness is fairly high even there are some limitations of the knowledge on causes and prevention of climate change. Further regression analysis resulted that the significant factors that determine awareness level are gender, year of education, and income; anyway, the result also indicated that most of the respondents have fair general knowledge about climate change in Oman. Nigatu et al. (2014) supported a slightly higher rate in females were aware of the health consequences of climate change. Climate change (CC) poses a major threat to public health $(\mathrm{PH})$; the barriers to $\mathrm{PH}$ engagement in addressing CC consist of individual perceptions and a lack of public health capacity, authority, and leadership; therefore, the efforts to increase PH should focus on education and communications, building leadership and funding as well as increasing work on the shared root causes of climate change and health inequities (Gould \& Rudolph, 2015). Extreme weather and climate events, especially in low and middle-income countries, are associated with a myriad of health outcomes including nutrition, mental illness, and exacerbation of underlying chronic diseases; hence, a better understanding of these events is needed (Ebi \&Bowen, 2016). The greatest barrier to public recognition of human-made climate change is probably the natural variability of local climate (Hansen et al. 2012).

Vardoulakis et al. (2015) focused on building overheating and thermal comfort, indoor air quality, indoor allergens, and infections as well as flood damages and water contamination in the UK; they found that groups at high risk of health effects include the elderly, individual with pre-existing illness, people, living in overcrowded accommodation and the socio-economically deprived. Furthermore, Capstick and Pidgeon (2014) confirmed that cold weather events in the UK were seen as pointing towards the reality of climate change and the people interpret these events based on the levels of pre-existing skepticism about CC. McMichael (2013) agreed “environmental researchers must argue for heightened public attention to today's macroenvironmental threats to present and future population health by emphasizing on the ecological dimension". 


\subsubsection{Bangladesh Perspective}

Kabir et al. (2016b) mentioned that livelihood patterns and overall health status of the people, especially affected by natural disasters such as cyclones, floods, drought, etc. Bangladesh are seriously affected by the impact of climate change. Kabir et al. (2016c) indicated that the marginalized population of Bangladesh are potentially at risk of climate change in the matter related to their health because they are suffering from climate change-related health impacts, and also urged the public health system of the country to take necessary steps in terms of adapting the impacts of climate change in the future.

Anwer (2012) stated that Bangladesh is frequently experiencing the adverse impacts of climate change such as the high intensity of cyclones and tidal surges, regular and long-lasting floods, encroaching salinity, river erosion, etc. that results forced migration of a significant number of people every year within the country or across the border based on connections and contacts in the receiving areas in search of livelihood. Ministry of Foreign Affairs of the Netherlands (2018) noted that Bangladesh is one of the most vulnerable countries to climate change and inclined to thrilling weather events such as floods, storm surges, cyclones, etc. due to its topography and geographical location where biophysical factors (floods and cyclones prone for being a flat, low, delta country) and socio-economic factors (such as population density, high dependence on agriculture and poverty) are responsible for its vulnerability.

Shahid (2010) presumed that human health can be affected directly as well as indirectly by climate change in several ways. Due to climate change, people of Bangladesh directly face natural disasters (such as floods, cyclones, droughts, etc.) heatwaves, stagnant weather etc. almost every year that causes losses of lives, serious illness, psychological distress, various diseases, etc. On the other hand, people of this country are indirectly affected by various infectious and skin diseases, by the impact of frequent floods, water-logging, variable precipitation, increased breeding of vectors, sea-level rise, groundwater over-exploitation, increased recharge in monsoon and groundwater pollution, droughts and lack of water, hostile conditions, decreased food production and malnutrition. As a result, various types of problems especially health-related problems such as life-threatening, infectious and skin diseases, vectorborne diseases, arsenicals etc. break out that suffer people a lot. Uddin et al. (2017) conducted a study on the coastal region of Bangladesh where they observed that climate change has severely affected the socio-economic conditions of the farmers. Due to temperature and salinity level rise, cyclones, droughts, floods, etc. and drop in rainfall, farmers are to suffer a lot at the 
time of crop production. Javed et al. (2020) found that increasing salinity due to adverse climate has both direct and indirect impacts on human health. People of coastal areas are to suffer from several diseases such as skin diseases, gastric, dysentery, high blood pressure, hair loss, diarrhea, etc. because of using saline water. They also observed that increasing salinity hampers crop cultivation in coastal areas and would be going to a serious threat in terms of availing water for drinking and household uses for the people living in these areas. Haque et al. (2012) revealed that climate variability such as increased heat, reduced rainfall, overall warmer winters, etc. have a negative effect in most cases on matters related to human health, means of living, agriculture, and overall livelihood.

\section{Research Methodology: \\ 4. 3.1 Research Design}

The study used the quantitative approach to analyze the public perceptions of CC impacts of HH in Bangladesh. This approach is adopted to capture the CC issues, its main causes, CC impacts on health and PP on CC's policies. This was done by applying the survey questionnaire. The study is largely exploratory, descriptive, and analytical in an attempt to assess the public perceptions of CC impacts on human health in Bangladesh. There were 615 people (based on sample size calculation) in this study who are described according to the data they provided regarding their age, gender, marital status, education, and income level.

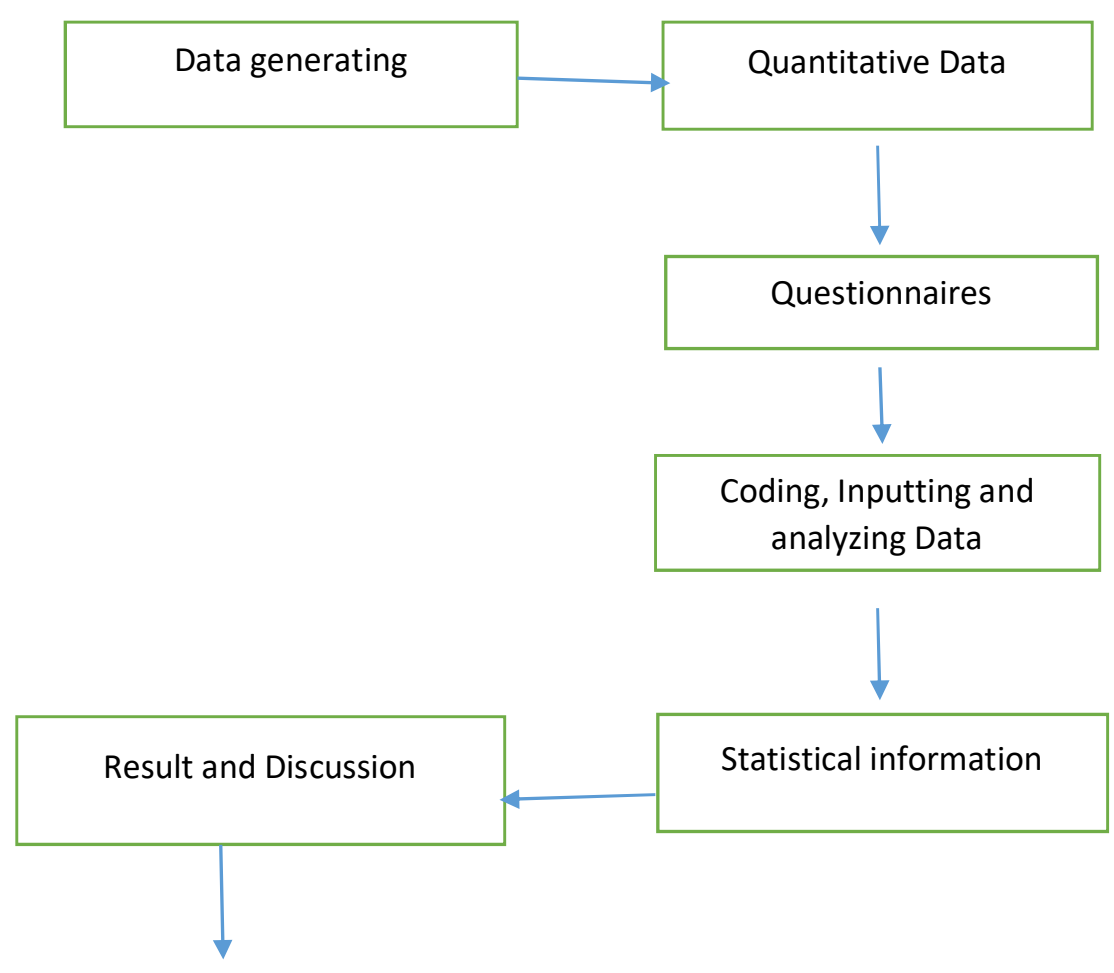


Conclusions and Recommendation 


\subsection{Study Area}

The study was conducted of ten UPs of ten different UPZs of ten different districts of Khulna, Rajshahi, Rangpur, Dianjpur, Chittagong, Barishal, Kushtia, Dhaka, Comilla, and Maymensingh which selected as the study area around eight divisions in Bangladesh.

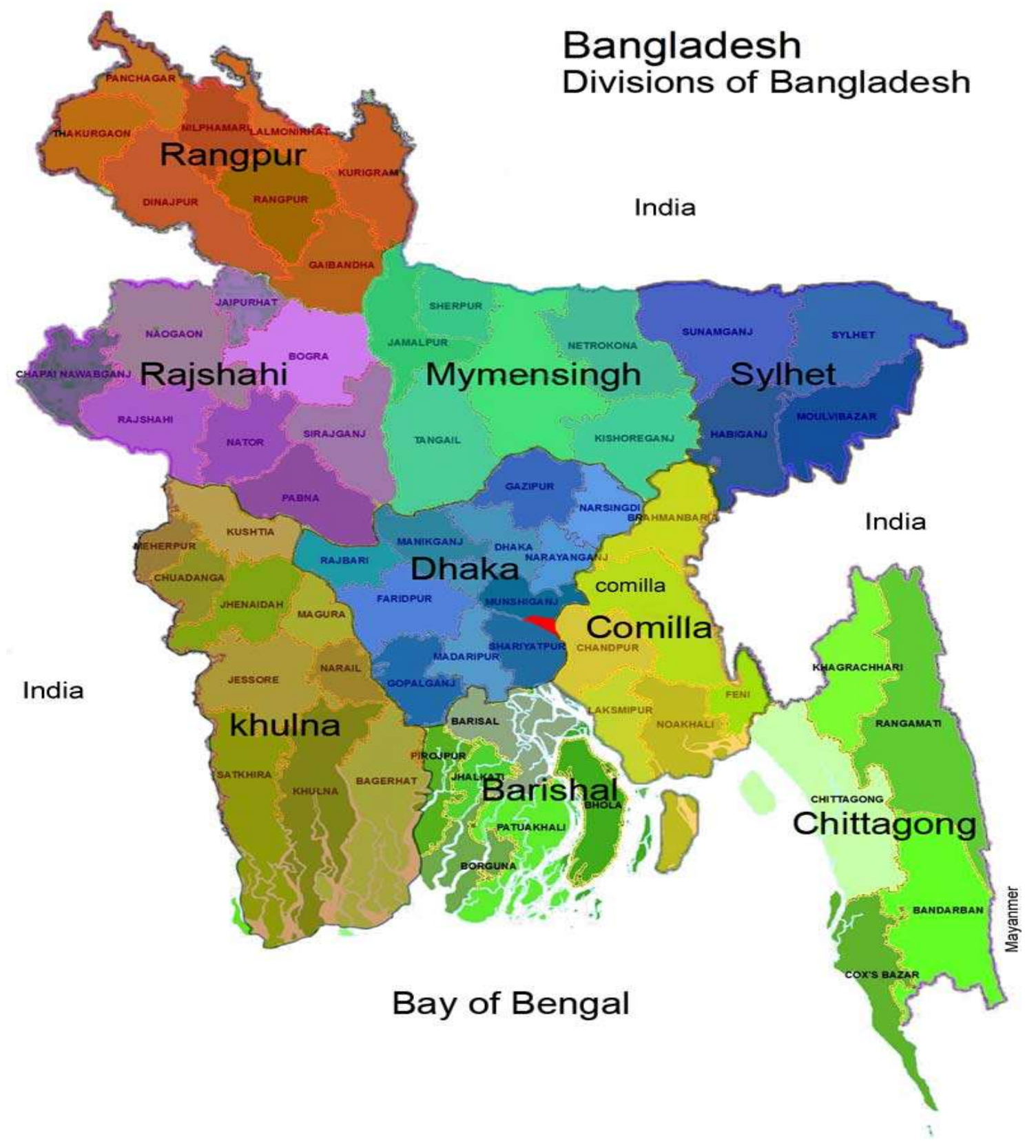




\subsection{Questionnaire Development}

In this study, items measurement, the 5-likert scale will be used (1= Strongly Disagree or very low, $5=$ Strongly agree or very high) to express the level of agreement or disagreement and frequency of respondents answer (Biswas et al., 2020). The first dimension comprised of seven items were adapted by Kabir et al. (2016a); Twum Barimah, (2015) and Wei, Hansen, ZhengLi, Liu, Sun and Bi (2014) including "Have you heard of CC before", "What are the main sources of your information on CC".

\section{Findings}

4.1. Demographic information of respondents

A total of 650 people were randomly selected for interview. Out of them, 615 (94.6\%) people have participated in the process. Table 4.1 shows the demographic information of respondents. In this study, the representation of males (71.7\%) was higher than in females (28.3\%). Most of the respondents (38.0\%) belong to 31-40 years' age group, followed by $26.8 \%$ from $21-30$ years age group and the last group's (3.4\%) age was 61 years or higher. Study data reveals that a significant number of respondents (13.7\%) had no education while $30.7 \%$ completed their primary education, followed by $21.5 \%$ who completed graduation, $17.6 \%$ who were able to complete high school education, $12.2 \%$ earned post-graduation degree and the tiniest group (4.4\%) completed college education. People from different categories in terms of their occupation were the respondents of this study where $19.5 \%$ each came from the farmer, student, and day laborer categories, followed by $9.8 \%$ each from teacher, businessman, housewife, and shopkeeper categories, and the remaining $2.4 \%$ consisted of others. $28.8 \%$ of respondents' income range fell between Tk. 5001 to Tk. 10000 , followed by $24.9 \%$ had no income because of being a student or housewife, $23.4 \%$ of respondents' income was equal or less than Tk. 5000 per month, 21.4\% of respondents' income range fell between Tk. 10001 to Tk. 40000 while only $1.5 \%$ of respondents' income was more than Tk. 40000 per month. 
Table 4.1: Demographic information of respondents $(N=615)$

\begin{tabular}{|c|c|c|}
\hline Variable & & Percentage $(\%)$ \\
\hline & Male & 71.7 \\
\hline & Female & 28.3 \\
\hline & $\leq 20$ & 10.7 \\
\hline & $21-30$ & 26.8 \\
\hline & $31-40$ & 38.0 \\
\hline & $41-50$ & 13.2 \\
\hline & $51-60$ & 7.8 \\
\hline & $\geq 61$ & 3.4 \\
\hline & No Education & 13.7 \\
\hline & Primary & 30.7 \\
\hline & High school & 17.6 \\
\hline & College & 4.4 \\
\hline & Bachelor & 21.5 \\
\hline & Masters or Above & 12.2 \\
\hline & Teacher & 9.8 \\
\hline & Farmer & 19.5 \\
\hline & Businessman & 9.8 \\
\hline Occupation & Housewife & 9.8 \\
\hline & Student & 19.5 \\
\hline & Day Labourer & 19.5 \\
\hline & Shopkeeper & 9.8 \\
\hline
\end{tabular}




\begin{tabular}{|l|l|l|} 
& Others & 2.4 \\
\hline \multirow{4}{*}{ Monthly Income (BDT) } & $\leq 5000$ & 23.4 \\
\cline { 2 - 3 } & $5001-10000$ & 28.8 \\
\cline { 2 - 3 } & $10001-20000$ & 11.2 \\
\cline { 2 - 3 } & $20001-40000$ & 10.2 \\
\cline { 2 - 3 } & $\geq 40001$ & 1.5 \\
\cline { 2 - 3 } & No Income & 24.9 \\
\hline
\end{tabular}

\subsection{Knowledge of climate change}

This section examined the respondents' knowledge of climate change especially to what extent they have an understanding of this issue. Figure 4.1 shows the ratio of respondents whether they heard about climate change before or not. The source of their existing knowledge about climate change is shown in Figure 4.2. Besides, cause of climate change, according to respondents' opinion based on of 5-point Likert Scale ranging from 'Strongly Disagree' (1) to 'Strongly Agree' (5), is shown in Table 4.2.

\section{Heard about climate change before or not $(N=615)$}

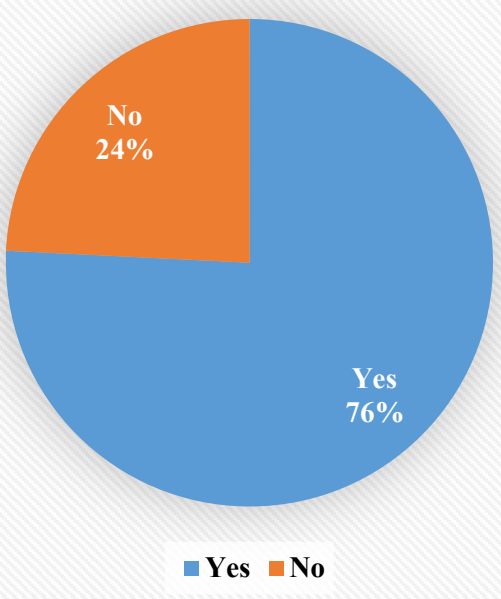

Figure 4.1: Heard about climate change before or not 


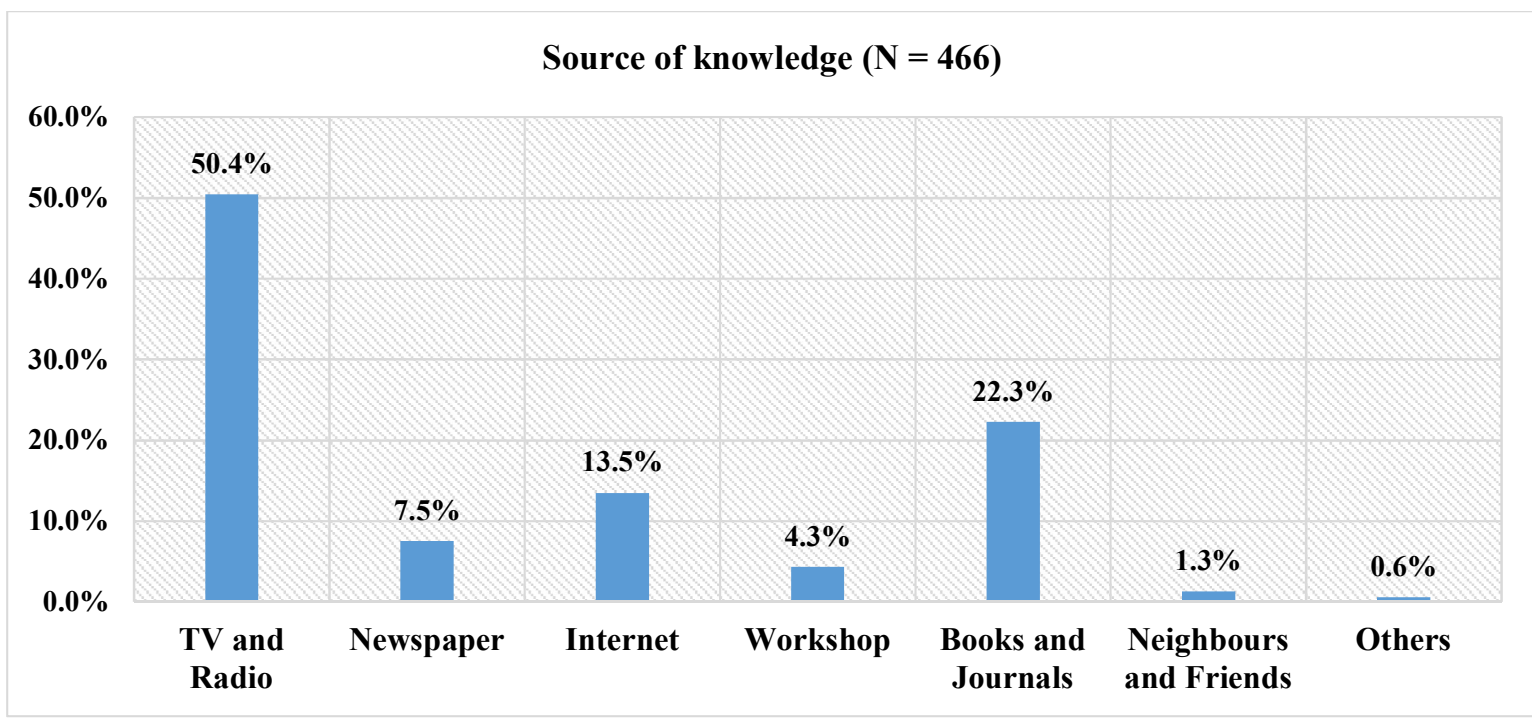

Figure 4.2: Source of knowledge

Table 4.2: Cause of climate change

\begin{tabular}{|c|c|c|c|c|c|c|c|}
\hline$(\mathrm{N}=466)$ Opinion & $\frac{2}{000}$ & 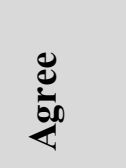 & 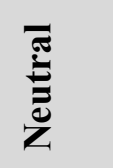 & 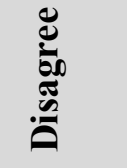 & 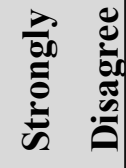 & 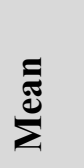 & \% \\
\hline $\begin{array}{l}\text { 1. I think human activities are } \\
\text { the main cause of climate } \\
\text { change }\end{array}$ & $33.7 \%$ & $50.9 \%$ & $0.0 \%$ & $12.9 \%$ & $2.6 \%$ & 4.00 & 1.042 \\
\hline $\begin{array}{l}\text { 2. I think natural factors are the } \\
\text { main cause of climate change }\end{array}$ & $8.4 \%$ & $39.9 \%$ & $0.0 \%$ & $47.0 \%$ & $4.7 \%$ & 3.00 & 1.181 \\
\hline
\end{tabular}

\subsection{Perception about the impact of climate change}

This section measured the respondents' perception of the impact of climate change especially their awareness of climate change impacts on human health (Table 4.3), their perception of climate change and diseases (Table 4.4), and their attitudes towards climate change policies (Table 4.5). The percentage is used to figure out the real picture of this segment especially perception-based questions ( 5 for strongly agree to 1 for strongly disagree or 5 for very high to 1 for very low). Moreover, the mean represents the general average of respondents' responses, while standard deviation indicates the difference of responses provided by the respondents to 
a question vary or deviate from the mean. The value of standard deviation is close to 1 of maximum cases, as shown in Table 4.3, Table 4.4, and Table 4.5 respectively by which it is clear that the response of each question is close to the average.

Table 4.3: Awareness of climate change impacts on human health $(N=466)$

\begin{tabular}{|c|c|c|c|c|c|c|c|}
\hline Opinion & 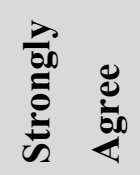 & 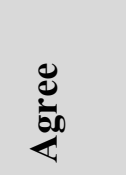 & 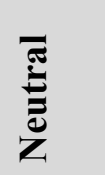 & 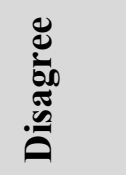 & 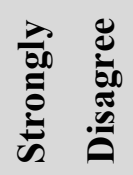 & 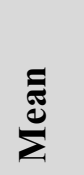 & हิ \\
\hline $\begin{array}{l}\text { 1. I think climate change has an } \\
\text { impact on human health }\end{array}$ & $42.1 \%$ & $50.4 \%$ & $0.0 \%$ & $7.5 \%$ & $0.0 \%$ & 4.27 & .806 \\
\hline $\begin{array}{l}\text { 2. I think climate change is a } \\
\text { serious threat to human health }\end{array}$ & $32.6 \%$ & $57.9 \%$ & $0.0 \%$ & $9.4 \%$ & $0.0 \%$ & 4.14 & .829 \\
\hline $\begin{array}{l}\text { 3. I think extreme heat and cold } \\
\text { / diseases / health problems / } \\
\text { sickness will increase }\end{array}$ & $42.7 \%$ & $47.6 \%$ & $0.0 \%$ & $9.2 \%$ & $0.4 \%$ & 4.23 & .885 \\
\hline $\begin{array}{l}\text { 4. I think change in rainfall } \\
\text { pattern in the last } 5 \text { years } \\
\text { increases health problem }\end{array}$ & $12.0 \%$ & $63.5 \%$ & $0.0 \%$ & $24.5 \%$ & $0.0 \%$ & 3.63 & .982 \\
\hline $\begin{array}{l}\text { 5. I think health risk increased } \\
\text { due to increase in salinity }\end{array}$ & $20.8 \%$ & $55.8 \%$ & $0.0 \%$ & $23.4 \%$ & $0.0 \%$ & 3.74 & 1.039 \\
\hline
\end{tabular}


Table 4.4: Perception on climate change and diseases $(N=466)$

\begin{tabular}{|c|c|c|c|c|c|c|c|}
\hline Question & $e^{2}$ & $\stackrel{50}{100}$ & 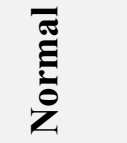 & 产 & $\stackrel{0}{D}$ & $\sum_{\Sigma}^{\mathbb{E}}$ & 光 \\
\hline $\begin{array}{l}\text { Q1. What is your overall } \\
\text { perception about diseases due } \\
\text { to climate change in } \\
\text { Bangladesh? }\end{array}$ & $23.4 \%$ & $51.9 \%$ & $16.1 \%$ & $8.6 \%$ & $0.0 \%$ & 3.90 & .854 \\
\hline $\begin{array}{l}\text { Q2. What is the present } \\
\text { frequency of diseases during } \\
\text { summer compared to } 5-10 \\
\text { years earlier? }\end{array}$ & $7.7 \%$ & $55.6 \%$ & $26.2 \%$ & $\begin{array}{l}10.5 \\
\%\end{array}$ & $0.0 \%$ & 3.61 & .778 \\
\hline $\begin{array}{l}\text { Q3. What is the present } \\
\text { frequency of diseases during } \\
\text { winter compared to } 5-10 \text { years } \\
\text { ago? }\end{array}$ & $10.5 \%$ & $56.4 \%$ & $23.6 \%$ & $9.4 \%$ & $0.0 \%$ & 3.68 & .786 \\
\hline $\begin{array}{l}\text { Q4. What is the present } \\
\text { frequency of diseases during } \\
\text { rainy seasons compared to } 5- \\
10 \text { years ago? }\end{array}$ & $4.1 \%$ & $56.0 \%$ & $29.4 \%$ & $\begin{array}{l}10.5 \\
\%\end{array}$ & $0.0 \%$ & 3.54 & .736 \\
\hline
\end{tabular}

Table 4.5: Attitudes towards climate change policies $(N=466)$

\begin{tabular}{|c|c|c|c|c|c|c|c|}
\hline Opinion & 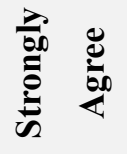 & 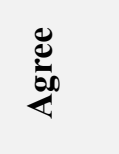 & Z & 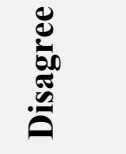 & 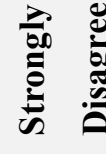 & $\sum_{\Sigma}^{\Xi}$ & ڤ \\
\hline $\begin{array}{l}\text { 1.The government can take active } \\
\text { measures responding to climate } \\
\text { change }\end{array}$ & $18.9 \%$ & $67.0 \%$ & $0.0 \%$ & $13.3 \%$ & $0.9 \%$ & 3.90 & .888 \\
\hline
\end{tabular}




\begin{tabular}{|l|l|l|l|l|l|l|l|}
\hline $\begin{array}{l}\text { 2. Fiscal and taxation policies can } \\
\text { play a positive role in dealing with } \\
\text { climate change }\end{array}$ & $14.4 \%$ & $67.4 \%$ & $0.0 \%$ & $16.1 \%$ & $2.1 \%$ & 3.76 & .961 \\
\hline $\begin{array}{l}3 . \quad \text { I am satisfied with the } \\
\text { government and emergency relief } \\
\text { organizations' response to climate } \\
\text { change impacts }\end{array}$ & $4.1 \%$ & $39.3 \%$ & $0.0 \%$ & $48.5 \%$ & $8.2 \%$ & 2.83 & 1.157 \\
\hline $\begin{array}{l}4 . \text { Personal behavior is important to } \\
\text { respond climate change }\end{array}$ & $18.7 \%$ & $50.6 \%$ & $0.0 \%$ & $29.0 \%$ & $1.7 \%$ & 3.56 & 1.143 \\
\hline $\begin{array}{l}\text { 5. I can make contribution to cope } \\
\text { with climate change }\end{array}$ & $17.2 \%$ & $56.2 \%$ & $0.0 \%$ & $24.0 \%$ & $2.6 \%$ & 3.61 & 1.104 \\
\hline
\end{tabular}

\section{Discussions}

5.1 Knowledge of climate change

\subsubsection{Heard about climate change before or not}

Though the study aims to assess the public perception about the impact of climate change on human health in the context of Bangladesh, it was necessary to know whether the respondents have knowledge about climate change and particularly if they have heard about climate change before. In response, $76.0 \%$ of the respondents replied positively while remaining $24.0 \%$, almost one-fourth of total respondents, indicated that they have not heard the term climate change before (Figure 4.1) which demands special attention for informing the unknown about the issue so that they can be able to take precautionary measures to save themselves from the harmful effect of climate change. When asked them about their understanding of various types of changes in climate, they mentioned global warming, deforestation, temperature rise, drought, heatwave, etc. in response. They also pointed out some problems such as physical and mental health hazard, sea-level rise, deterioration of environmental ecosystem, excessive rain, extreme weather, increasing diseases and illness, natural disaster, etc. will take place as a result of climate change while talking about the impact of climate change.

\subsubsection{Source of knowledge}

Respondents, 466 in number, who have heard about climate change before were also requested to mention the source of their information especially from where they have known about 
climate change. In reply, more than half of the respondents (50.4\%) mentioned TV (Television), and radio as their source of information while $13.5 \%$ got information about climate change through internet by using their mobile phones or computers which indicates modern technologies like computer, mobile phone, TV, radio, etc. are playing a crucial role to make the unknown people known about any important matter like climate change. Moreover, $22.3 \%$ of respondents knew this matter by reading various books and journals while $7.5 \%$ by reading newspapers. Furthermore, $4.3 \%$ of respondents, particularly farmers, got knowledge of climate change in participating in various workshops arranged by the agriculture extension department or various NGOs working in this field. Besides, $1.3 \%$ came to know the matter from their neighbors and friends, and the remaining 0.6\% from others (Figure 4.2).

\subsubsection{Cause of climate change}

When the respondents, 466 in number, were asked to express their perception about the cause of climate change, the majority of the respondents opined that human activities are responsible in this case. Table 4.2 shows that $84.6 \%$ of respondents agreed on the opinion that hum activities are the main cause of climate change. On the contrary, less than half of the same respondents $(48.3 \%)$ voted in favor of the opinion that natural activities are the main cause of climate change. From this segment, it is clear that people are solely responsible to upgrade or deteriorate the environment through their activities and it is possible to reduce environmental degradation, particularly changes in climate if people behave sensibly.

\subsection{Perception about the impact of climate change}

\subsubsection{Awareness of climate change impacts on human health}

Out of 466 respondents, knowledgeable in climate change, $92.5 \%$ of respondents agreed that climate change has an impact on human health while only $7.5 \%$ of respondents disagreed with this statement. $90.5 \%$ of respondents argued that they are agreed with the opinion that climate change is a serious threat to human health (Table-3) which is similar to the findings of Toan et al. (2014) and Nigatu et al. (2014) who mentioned that climate change is an emerging threat to public health. Primary data also revealed that $90.3 \%$ of respondents believe that extreme heat and cold /diseases/ health problems /sickness will increase due to climate change while only $9.6 \%$ differ the statement. $75.5 \%$ of respondents claimed that change in rainfall patterns in the 
last 5 years increases health problems. In addition, $76.6 \%$ of respondents stated that health risk increased due to an increase in salinity (Table 4.3). So, effective steps should be taken as early as possible to face this emerging threat so that public health may be secured.

\subsubsection{Perception of climate change and diseases}

Primary data revealed that more than sixty percent of respondents, 466 in number, believe that people of Bangladesh are currently facing more diseases due to climate change than that of 510 years ago. In response to the question i.e., what is your overall perception about diseases due to climate change in Bangladesh?, almost three-fourth of total respondents (74.3\%) marked their reply as high while $16.1 \%$ termed it as normal and the remaining $8.6 \%$ of respondents categorized it as low. In a separate query on season-based disease scenario, $63.3 \%$ of respondents opined that the present frequency of diseases during summer is high compared to 5 - 10 years earlier, while $26.2 \%$ mentioned it as normal and $10.5 \%$ labeled it as low. In addition, $66.9 \%$ of respondents told that the present frequency of diseases during winter is high compared to 5 - 10 years ago, while $23.6 \%$ of respondents marked it as normal and $9.4 \%$ of respondents figured it as low. Furthermore, $60.1 \%$ of respondents stated that the present frequency of diseases during the rainy season is high compared to $5-10$ years ago, while $29.4 \%$ mentioned it as normal and the remaining 10.5\% termed it low (Table 4.4). So, concerned authorities should take necessary measures in this matter to keep people safe from the diseases break out due to climate change throughout the year.

\subsubsection{Attitudes towards climate change policies}

The findings of this study revealed that $85.9 \%$ of respondents, out of 466 , believe that the government can take active measures responding to climate change, while $14.2 \%$ of respondents stated that the government cannot take active measures in this case. But the matter of fact that, although the majority respondents have shown their faith on the capacity of government, only $43.4 \%$, almost half of $85.9 \%$, respondents are satisfied with the government and emergency relief organizations' response to climate change impacts at present time, while $56.7 \%$ respondents expressed their dissatisfaction regarding the actions taken by the government and emergency relief organizations. In this case, fiscal and taxation policies can play a positive role especially in dealing with climate change because primary data exposed that $81.8 \%$ of respondents have favored these policies. In addition, $69.4 \%$ of respondents agreed that personal behavior is important to respond to climate change, while $73.4 \%$ seemed that they can make a contribution to cope with climate change (Table 4.5). 
From the above discussion, it is clear that there is no alternative of awareness-raising among mass people about the impact of climate change, while common people must have to follow the guidelines to keep themselves healthy in spite of climate change as well as people have to come forward to face the impacts of climate change. So, it is high time, the government and other agencies should rethink and take decisive steps in this regard.

\section{Conclusion:}

The World Health Organization intensified that climate change is a crucial and emerging issue to human health, particularly lower-income societies or tropical countries. However, people especially, Asia and Africa has the least perceived climate change as a threat to human health. Bangladesh is one of the most vulnerable countries of climate change in the world (Kabir, 2016a). The study explored the public perceptions of climate change and its impacts on human health in Bangladesh based on lesson learned from South and south-east Asian LDCs like Nepal, Cambodia, Bhutan, Lao PDR as well as some other countries such as China, UK, USA, India, Canada, Nigeria, Spain, Oman, Poland, and Zimbabwe. This study has also contributed informatively to the scant information on the impacts of climate change affecting human health in Bangladesh. Theoretically, the study has contributed to the previous literature on the public perceptions of climate change impacts on human health. The most of the participants had some knowledge about Climate change and they stated that both human and natural activities are the causes of climate change while the majority of them believed that climate change has a huge impact on human health than before. Furthermore, the results of the study will be very useful for climate change policymakers especially the Ministry of Environment and Forest and Climate Change (MoEFCC) for making related policies and mechanisms in order to overcome with current human health impacts in Bangladesh. In addition, the awareness of existence, the impacts, and the causes of climate change will be possible to integrate climate change into policy planning, projects, and daily activities as well as make the whole society to participate in the entire process to mitigate climate change. Furthermore, the findings of this study will assist policymakers, development partners, and NGOs working in climate perception to designate the policies and strategic plans to prevent the diseases causing climate change and to promote individuals to address climate change in Bangladesh. 


\section{References}

Akerlof, K., DeBono, R., Berry, P., Leiserowitz, A., Roser-Renouf, C., Clarke, K. L., \& Maibach, E. W. (2010). Public perceptions of climate change as a human health risk: surveys of the United States, Canada and Malta. International journal of environmental research and public health, $7(6), 2559-2606$.

Akerlof, K. L., Delamater, P. L., Boules, C. R., Upperman, C. R., \& Mitchell, C. S. (2015). Vulnerable populations perceive their health as at risk from climate change. International journal of environmental research and public health, 12(12), 15419-15433.

Al Buloshi, A.S. and Ramadan, E., (2015). Climate change awareness and perception amongst the inhabitants of Muscat Governorate, Oman. American Journal of Climate Change, 4(04), p.330.

Alhassan, S. and Hadwen, W.L., (2017). Challenges and opportunities for mainstreaming climate change adaptation into WaSH development planning in Ghana. International journal of environmental research and public health, 14(7), p.749.

Amzat, J. and Razum, O., (2014). Health, disease, and illness as conceptual tools. In Medical sociology in Africa (pp. 21-37). Springer, Cham.

Anwer, S. (2012). Climate Refugees in Bangladesh: Understanding the migration process at the local level. Diakonisches Werk der EKD eV.

Bangladesh Bureau of Statistics (BBS), (2019a). Statistical Pocket Book Bangladesh 2018. Dhaka, Bangladesh: BBS.

Bangladesh Bureau of Statistics (BBS), (2019b). Statistical Year Book Bangladesh 2018 (38 ${ }^{\text {th }}$ Edition). Dhaka, Bangladesh: BBS.

Bircher, J., (2005). Scientific Contribution Towards a dynamic definition of health and disease. Medicine, Health Care and Philosophy, 81335, p.341.

Biswas, B., Roy, S. K., \& Roy, F. (2020). Students Perception of Mobile Learning during COVID-19 in Bangladesh: University Student Perspective. Aquademia, 4(2), ep20023. https://doi.org/10.29333/aquademia/8443 
Bose, P. (2017). Climate adaptation: marginal populations in the vulnerable regions. Climate and Development, 9(6), 575-578.

Capstick, S.B. and Pidgeon, N.F., (2014). Public perception of cold weather events as evidence for and against climate change. Climatic Change, 122(4), pp.695-708.

Chean, R. (2017). Perceptions, Attitudes and Behaviour around Climate Change Risks on Livelihood Activities: A Case Study of a Community in Takeo Province, Cambodia.

Chhinh, N. and Poch, B., (2012). Climate change impacts on agriculture and vulnerability as expected poverty of Kampong Speu Province, Cambodia. International Journal of Environmental and Rural Development, 3(2), pp.28-37.

Chhinh, N., \& Cheb, H. (2013). Climate change vulnerability: households assessment level in Kampong Speu Province. Cambodia', International Society of Environmental and Rural Development, 4(1), 31-38.

Didovets, I., Lobanova, A., Bronstert, A., Snizhko, S., Maule, C.F. and Krysanova, V., (2017). Assessment of climate change impacts on water resources in three representative Ukrainian catchments using eco-hydrological modelling. Water, 9(3), p.204.

Dowler, E., Green, J., Bauer, M., \& Gasperoni, G. (2006). Assessing public perception: issues and methods. Health hazard and public debate: lessons for risk communication from BSE/CJD saga. Geneva: World Health Organization, 40, 60.

Ebi, K.L. and Bowen, K., (2016). Extreme events as sources of health vulnerability: Drought as an example. Weather and Climate Extremes, 11, pp.95-102.

Environmental Performance Index (EPI), (2020). Retrived at https://epi.yale.edu/epiresults/2020/component/epi

Gould, S. and Rudolph, L., (2015). Challenges and opportunities for advancing work on climate change and public health. International journal of environmental research and public health, 12(12), pp.15649-15672.

Hansen, J., Sato, M., \& Ruedy, R. (2012). Perception of climate change. Proceedings of the National Academy of Sciences, 109(37), E2415-E2423. 
Haque, M.A., Yamamoto, S.S., Malik, A.A. and Sauerborn, R., (2012). Households' perception of climate change and human health risks: A community perspective. Environmental Health, 11(1), p.1.

Jabed, M. A., Paul, A., \& Nath, T. K. (2020). Peoples' perception of the water salinity impacts on human health: A case study in South-Eastern Coastal Region of Bangladesh. Exposure and health, 12(1), 41-50.

Kabir, M.I., Rahman, M.B., Smith, W., Lusha, M.A.F., Azim, S. and Milton, A.H., (2016a). Knowledge and perception about climate change and human health: findings from a baseline survey among vulnerable communities in Bangladesh. BMC public health, 16(1), p.266.

Kabir, R., Khan, H. T. A., Ball, E. and Caldwell, K. (2016b). Climate change impact: the experience of the coastal areas of Bangladesh affected by cyclones Sidr and Aila. Journal of Environmental and Public Health, 2016, p.9.

Kabir, M. I., Rahman, M. B., Smith, W., Lusha, M. A. F., \& Milton, A. H. (2016). Climate change and health in Bangladesh: a baseline cross-sectional survey. Global health action, 9(1), 29609.

Markandya, A. and Chiabai, A., (2009). Valuing climate change impacts on human health: empirical evidence from the literature. International Journal of Environmental Research and Public Health, 6(2), pp.759-786.

McMichael, A. J. (2013). Globalization, climate change, and human health. New England Journal of Medicine, 368(14), 1335-1343.

Miyan, M. A. (2015). Droughts in Asian least developed countries: Vulnerability and sustainability. Weather and Climate Extremes, 7, 8-23.

Ministry of Environmrnt, Forest and Climate Change, (2018). Retrived at https://moef.gov.bd/

Ministry of Foreign Affairs. (2018). Climate Change Profile: Bangladesh. The Hague, The Netherlands: Ministry of Foreign Affairs of the Netherlands.

Nigatu, A. S., Asamoah, B. O., \& Kloos, H. (2014). Knowledge and perceptions about the health impact of climate change among health sciences students in Ethiopia: a cross-sectional study. BMC Public Health, 14(1), 1-10. 
Protocol, K. (1997). United Nations framework convention on climate change. Kyoto Protocol, Kyoto, $19,497$.

Toan, D. T. T., Kien, V. D., Giang, K. B., Minh, H. V., \& Wright, P. (2014). Perceptions of climate change and its impact on human health: an integrated quantitative and qualitative approach. Global health action, 7(1), 23025.

Saracci, R. (1997). The World Health Organisation needs to reconsider its definition of health. Bmj, 314(7091), 1409.

Shahid, S. (2010). Probable impacts of climate change on public health in Bangladesh. Asia Pacific Journal of Public Health, 22(3), p.310-319.

Sour, K., Phalla, C. H. E. M., Sovannarith, S., Somatra, K. S., \& Sokhem, P. E. C. H. (2014). Methods and tools applied for climate change vulnerability and adaptation assessment in Cambodia's Tonle Sap Basin. Phnom Penh: Cambodia's leading independent development policy research institute (CDRI).

Teodorescu, G., \& Oros, C. (2010). Development of education on environmental and climate change impacts in Romania. Procedia-Social and Behavioral Sciences, 2(2), 5502-5506.

Tvinnereim, E., Liu, X., \& Jamelske, E. M. (2017). Public perceptions of air pollution and climate change: different manifestations, similar causes, and concerns. Climatic Change, 140(3-4), $399-412$.

Twum Barimah, N. (2015). Comparison of extraction methods for the determination of available phosphorus in some selected soils from the Eastern region of Ghana (Doctoral dissertation).

Uddin, M. N., Bokelmann, W. and Dunn, E. S. (2017). Determinants of farmers' perception of climate change: a case study from the coastal region of Bangladesh. American Journal of Climate Change, 6, p.151-165.

Vardoulakis, S., Dimitroulopoulou, C., Thornes, J., Lai, K. M., Taylor, J., Myers, I., \& Davies, M. (2015). Impact of climate change on the domestic indoor environment and associated health risks in the UK. Environment International, 85, 299-313.

World Health Organization. (1948). Preamble to the Constitution of the World Health Organization as adopted by the International Health Conference, New York, 19-22 June, 1946; signed on 22 July 1946 by the representatives of 61 States (Official Records of the World Health 
Organization, no. 2, p. 100) and entered into force on 7 April 1948. http://www.who. int/governance/eb/who_constitution_en. pdf. 